Atıfta Bulunmak İçin / Cite This Paper: Öztürk, A. (2019). "Fast Food Restoranlarının Tercih Edilmesinde Etkili Olan Faktörlerin Ahs Metodu İle Önceliklendirilmesi", Manas Sosyal Araştırmalar Dergisi, 8(3): 2679-2695

Araştırma Makalesi

\title{
FAST FOOD RESTORANLARININ TERCIH EDILMESINDE ETKILI OLAN FAKTÖRLERIN AHS METODU ILLE ÖNCELIKLENDIRILMESI
}

\author{
Dr. Öğr. Üyesi Aziz ÖZTÜRK \\ Selçuk Üniversitesi, Beyșehir Ali Akkanat İşletme Fakültesi \\ azizozturk@selcuk.edu.tr \\ ORCID ID: 0000-0003-1355-6078
}

\begin{abstract}
$\ddot{O} \mathbf{z}$
$\mathrm{Bu}$ çalışmanın amacı tüketicilerin fast food restoranları seçiminde etkili olan faktörleri tanımlamak ve bu faktörleri önceliklendirmektir. Bu amaçla yiyecek içecek servisi verilen işletmeler tercih edilirken tüketiciler tarafindan algılanan önemli faktörleri tanımlamak üzere literatür taraması yapılmıştır. Çalışmada literatüre göre fast food restoranlarının seçiminde etkili olan fiyat, temizlik, yiyeceklerin tadı ve lezzeti, personelin yardım severliği ve tutumu, servis hızı, marka bilinirliği, menü çeşitliliği, ortam/ambiyans, restoranın konumundan oluşan dokuz kritere yönelik analizler yapılmıștır. Analiz yöntemi olarak Analitik Hiyerarși Süreci (AHS) yöntemi kullanılmıştır. AHS, çok kriterli durumlar karşısında karşılaştırmalı olarak kriterlerin önceliklendirmesinde ve en iyi performans gösteren birimlerin belirlenmesinde uygulanmaktadır. Analize ilişkin verilerin toplanmasında anket yöntemi kullanılmıştır. Anketler S.Ü. Beyșehir Ali Akkanat Kampüsünde okuyan 180 üniversite öğrencisine basit örnekleme yöntemiyle seçilmek suretiyle uygulanmıştır. Araştırma bulgularına göre tüketicilerin fast food restoranların tercih ederken en fazla etkilendikleri faktörler; Temizlik, Yiyeceklerin Tadı ve Lezzeti ve Personelin Tutumu şeklinde sıralanmıştır.
\end{abstract}

Anahtar Kelimeler: Fast Food, Pazarlama Etkinliği, Müșteri Tercihi, AHS

\section{PRIORITIZATION OF THE FACTORS AFFECTING THE PREFERENCE OF FAST FOOD RESTAURANTS WITH AHS METHOD}

\begin{abstract}
Comparisons towards the effectiveness of marketing activities of businesses have not taken much place in marketing literature due to the lack of appropriate methodological means to assist the benchmarking process. Besides, studies evaluating the performance of food and beverage companies are occasional. This study aims to contribute to both points and prioritizes the factors that are effective in customers' purchasing. For this purpose, human behaviors have been analyzed based upon multiple criteria such as price, customer service, environment, cleanliness, service speed, location, which are stated to be effective in the selection of fast food restaurants in the literature. Analytical Hierarchy Process (AHP) method was used as analysis method. AHP is useful in prioritizing criteria comparatively and identifying the best performing units under multiple criteria circumstances. Four fast food restaurant brands were included in the study and were evaluated over six criteria. Survey method was used for data collection. The surveys were applied to the university students studying at Beyşehir Ali Akkanat campus by selecting with simple random method.
\end{abstract}

Keywords: Fast Food, Marketing Effectiveness, Customer Preference, AHP 


\section{GİRIS}

Fast food, üretilmesi ve servis edilmesi toplamda birkaç dakikayı aşmayan, ucuz ve tek kullanımlık ambalajı olan, elle tutularak yenen bir gıda kategorisi olarak, tüm dünyada ciddi bir büyüklüğe ulaşmış durumdadır (Marketing Türkiye, 2017). Hızlı hazırlanması, tüketim ve taşıma kolaylığı nedeniyle fast food, insanların yemek tercihinde favori seçeneklerden birisidir (Siew vd., 2017). Fast food restoranlar ise bu gıda grubunu sunarak insanların yiyecek içecek ihtiyaçlarını karşılamak üzere hizmet veren işletmelerdir.

Hızlı nüfus artışının etkisiyle kentleşme oranındaki artışa, kadınların çalışma yaşamına girmesine, buna bağlı olarak aile gelir düzeylerinin yükselmesine, dışarıda yeme alışkanlığının yerleşmesine, çalışma yaşamındaki artan temponun yemeğe ayrılan süreyi kısaltmasına, genç nüfus oranındaki artışa ve reklamların etkisine bağlı olarak fast food sektörü her geçen gün biraz daha büyümektedir (Kecek ve Gürdal, 2016; Marketing Türkiye, 2017).

1986 yılında McDonald'ın Türkiye pazarına girmesiyle sektörün Türkiye'deki büyümesi ivme kazanmış son yıllarda ise pek çok yerli ve yabancı markanın hakim olduğu büyük bir pazar haline gelmiştir. Türkiye fast food pazarında yabancı sermayeli fast food markalarının hâkimiyetine rağmen yerli firmalar da hamburger, pizza, sosis ekmek, sandviç, lahmacun, pide, köfte, gözleme, döner, tost, börek, kokoreç midye, çiğ köfte ve simit gibi ürünlerle markalaşarak büyümeye çalışmaktadırlar. Türkiye'nin fast food tercihlerinin ve alışkanlıklarının incelendiği bir araştırmaya göre Burger King, Domino’s, Mc Donald's, Baydöner, KFC, Hacıŏlu, PopeYes, Army's Türkiye'de en çok tercih edilen Fast Food markalarıdır (Marketing Türkiye, 2017).

Günümüz fast food restoran yöneticileri benzeri az görülür bir meydan okumayla karşı karşıyadırlar. Swanger (1998)'a göre restoran pazarında az sayıda müşteriyi kovalayan çok sayıda işletme bulunmaktadır. Artan müşteri talepleri ve beklentileri ile piyasa oyuncuları arasındaki rekabet daha da zorlaşmaktadır (Mammadli, 2016). Florida Üniversitesinin sektörler araştırmasına göre restoran sektörü, diğer hizmet sektörlerine kıyasla en düşük performans ve ticari başarısızlık oranına sahip sektördür. Parsa vd. 'ne (2011) göre, kötü performans ve iş başarısızlıklarının nedeni; artan müşteri talepleri, ihtiyaçları ve beklentilerine cevap verilememesidir (Parsa vd., 2011).

Günümüz müşterileri, talep ve ihtiyaçları karşılanırken, kendilerini tatmin edecek bir değerin de sunulmasını beklemektedirler. Bu olmadığı takdirde düşük müşteri memnuniyeti, yüksek pazar kaybı ve sonuçta azalan kar marjı gibi istenmeyen sonuçlar ortaya çıkabilmektedir (Mammadli, 2016). 
$\mathrm{Bu}$ nedenle restoran işletmecilerinin / yöneticilerinin, müşteri algılarının farkında olmaları ve tüketicilerin satın alma davranışlarına yön veren faktörleri belirlemek ve bu faktörler üzerinden değer sunabilmek için tüketici davranışlarını sistematik olarak gözden geçirmeleri kritik öneme sahiptir. Fast food sektörü gibi rekabetçi bir sektörde, işletme sahiplerinin ve pazarlama yöneticilerinin, işlerinin pek çok yönüne ilişkin tüketici davranışlarına yönelik güncel bilgilere sahip olması gerekmektedir.

$\mathrm{Bu}$ bağlamda çalışmanın amacı, tüketicilerin fast food restoranları seçiminde etkili olan karar faktörlerinin önceliklendirilmesidir. $\mathrm{Bu}$ amaçla çalışmada bundan önceki araştırmalarda sıklıkla kullanılan; Fiyat, Temizlik, Yiyeceklerin Tadı ve Lezzeti, Personelin Yardım Severliği ve Tutumu, Servis Hızı, Marka Bilinirliği, Menü Çeşitliliği, Ortam/Ambians, Restoranın Konumu (Mammadli, 2016; Ehsan, 2012; Siew vd., 2018; Siew vd., 2017) kriterleri, fast food restoranlarının seçiminde etkili olan ana karar faktörleri olarak belirlenmiştir. Tüketiciler tarafından bir fast food restoranının seçiminde etkili olduğu düşünülen bu dokuz faktör çok kriterli karar verme yöntemlerinden olan Analitik Hiyerarşi Süreci (AHS) yöntemi kullanılarak bir sıralamaya tabi tutulmuştur. Böylece fast food restoranların seçiminde etkili olan faktörler tüketici bakış açısına göre önceliklendirilmiştir.

\section{LITERATÜR}

Fast food, insanların yaşamlarını daha verimli bir şekilde sürdürebilmeleri için beslenmeye daha az zaman ayırmalarının zorunlu bir sonucu olarak daha çok kentsel yaşam alanlarında etkisi hissedilen bir beslenme şeklidir (Kecek ve Gürdal, 2016). Fast food, hızlı ve kolay bir şekilde hazırlanan ve servis edilen, restoranlarda ve snack barlarda satılan ucuz gıda anlamına gelmektedir (Mammadli, 2016). Fast food, insanların yemek seçimi arasında favori seçimlerden biridir. Yerinde tüketime ve paket olarak taşınmaya uygun, kısa zamanda hazırlanabilmesi nedeniyle tercih edilmektedir (Siew vd., 2017).

Payne (2014), fast food restoranlarının genellikle standart gıdalar, tatlar, pişirme yöntemleri ve / veya merkezi olarak tedarik edilen şebekelerden her bir restorana sevk edilen kısmen hazırlanmış ürünler kullanan bir franchise veya restoran zincirine ait olduğunu belirtmektedir (Mammadli, 2016).

Fast food pazarı, işletmenin kendi restoranında veya diğer gıda hizmeti sunan işletmecileri ile paylaşılan belirlenmiş yemek alanlarında hızlı tüketilmesi gereken yiyecek ve içeceklerin satışı olarak tanımlanmaktadır (Ehsan, 2012).

Çoğu fast food restoranındaki menüler genellikle hamburger, kızarmış patates, kızarmış tavuk parçaları, sandviçler, gazlı meşrubatlar, kahve, salatalar, meyve suları, ızgara tavuk ve fırınlanmış patates gibi seçeneklerden oluşur. Gıda masraflarını azaltmak için 
genellikle plastik veya karton kutularda veya kâğıt ambalajlarda servis yapılır. Bu tür ambalajlar, yiyecekleri daha uzun süre sıcak tutar, bakteri bulaşmasını önler, kolay saklama ve nakliye sağlar (Mammadli, 2016).

Bugün fast food, dünyanın her köşesine yayılmış milyonlarca dolarlık bir sektördür. McDonald's, Burger King, KFC gibi önde gelen fast food zincirleri, dünya genelindeki çok uluslu işletmelerdir. Schlosser'e (2001) göre Amerikalılar, yükseköğrenime, kişisel bilgisayarlara, yazılımlara veya yeni arabaya göre daha fazla harcamayı fast fooda yapmaktadırlar. Benzer şekilde Jones (2002), fast food endüstrisini ülke ekonomisinde önemli bir segment olarak görmektedir (Mammadli, 2016).

Fast food restoran yöneticileri, fast food satış noktaları ve kültürler / ülkeler arasında tüketicilerin nasıl farklılaştıklarını, algılarını ve tercihlerini bilmelidirler. Böylece bu bilgiler yöneticiler tarafından restoranlarının algılarını iyileştirmek ve talebi arttırmak için kullanılabilecektir (Ehsan, 2012).

Çalışma, tüketicilerin bir fast food restoran seçerken değerli gördükleri faktörleri önceliklendirmeyi amaçlamaktadır. Yapılan çalışmalar göstermektedir ki restoranların seçimi veya reddi için kritik faktörler gıda kalitesi ve gıda çeşitliliğidir. Bu faktörlere ek olarak, müşteriler hızlı servis verilen restoranları tercih etmektedirler. Son çalışmalarda, yemeğin lezzeti, restoranın temizliği, yiyeceğin sıcaklığı, kalitesi, fiyatı, hizmet hızı, kolaylık / nezaket, ortamın rahatlığı, menü öğelerinin çeşitliliği, sağlıklı gıdaların mevcudiyeti ve çocuklara yönelik menü bulunması gibi kriterlerin restoran seçimindeki etkileri incelenmiştir. Sonuçlar hem erkeklerin hem de kadınların fast food restoranlarını tercih ettikleri ancak farklı çekim faktörleri tarafından etkilendiklerini göstermektedir (Ehsan, 2012).

Çalışanların işbirliği, restoranların sağladığı hizmetler, yiyeceklerin tadı, fiyat ve gece geç saatlerde hizmetlerin sunulması nedeniyle erkeklerin fast food'a yöneldiği görülmüştür. Kadınlar için ise marka imajı, lokantanın konumu, gıda kalitesi ve ambalajlama tarzı restoranın seçiminde önemli olan faktörlerdir (Aziz ve Bukhari, 2009).

Aziz ve Bukhari'nin (2009) çalışmasında, fiyat, gıda kalitesi, sağlanan hizmetler, paketleme tarzı, gıda tazeliği, zamanında teslimat, yiyecek çeşitliliği, gece geç saatlerde hizmet verme, arkadaşlarla toplanma yeri olarak tercih edilme, marka imajı, restoran ortamı, lokasyon ve çalışanların işbirliği faktörleri üzerinde çalışılmıştır (Aziz ve Bukhari, 2009).

Ehsan (2012), Pakistan'ın farklı üç şehrinde fast food restoranlarının seçimini etkileyen faktörlerin önem düzeyinin belirlenmesine yönelik bir çalışma yapmıştır. $\mathrm{Bu}$ çalışmada restoranın marka imajı, çevresi, lokasyonu, çalışanların işbirliği, fiyatları, tanıtım ve promosyon, hızlı servis, oturma alanı, yiyeceklerin lezzeti, yiyecek çeşitliliği olmak on 
faktör analiz edilmiştir. A şehrinde en önemli dört faktörün hızlı servis, restoranın imajı, tanıtım ve promosyon ve fiyatlar olduğu görülmüştür. B ve C şehrinde en önemli faktörler ise yiyeceklerin çeşitliliği, hızlı servis, tanıtım ve promosyon, fiyatlar şeklindedir (Ehsan, 2012).

Azim vd. (2014) müşterilerin restoran seçimini etkileyen en önemli ve etkili faktörleri belirleyemeye yönelik yapmış oldukları çalışmada restoranın fiziksel çevresi, temizlik, hızlı servis, çalışanların tutumu ve işbirliği, mahremiyet, fiyat, restoranda yer bulunabilirliği, yiyeceklerin lezzeti ve kalitesi, ayrıcalıklı hizmet, aileler için uygun ortam, marka imajı olmak üzere onbir faktör kullanmışlardır. Faktörlerin hepsinin restoran seçiminde etkili olduğu sonucuna varılmıştır. Bununla birlikte bu faktörler arasında yiyeceklerin lezzeti ve kalitesi, temizlik, fiziksel çevre, çalışanların tutumu ve işbirliği ve aileler için uygun ortam faktörlerinin restoran seçiminde müşterileri çok daha fazla etkilediği sonucuna ulaşılmıştır (Azim vd., 2014).

Goyal ve Singh (2007) restoran seçimine etki yapan temel faktörleri belirlemek amacıyla yaptıkları çalışmada menü çeşitliliği, yiyeceklerin lezzeti ve kalitesi, ambiyans ve hijyen, servis hızı, fiyat ve restoranın lokasyonu olmak üzere altı faktör kullanmışlardır (Goyal ve Singh, 2007).

Yukarıda bahsi geçen çalışmalarda tüketicinin restoran seçiminde etkili olduğu düşünülen ve sıklıkla kullanılan dokuz faktör bu çalışmada kullanılmıştır. Bunlar; yiyeceklerin tadı ve kalitesi, temizlik, personelin yardım severliği ve tutumu, menü çeşitliliği, servis hızı, restoranın konumu, fiyat, ortam/ambiyans, marka bilinirliği (Mammadli, 2016; Ehsan, 2012; Siew vd., 2018; Siew vd., 2017, Azim vd., 2014) şeklindedir.

Başarılı bir restoran her zaman rakiplerinden farklı olmayı istemelidir. Müşterileri etkileyebilecek bir farklılık, restoranın rakiplerine göre daha fazla tercih edilmesini ve pazarda daha güçlü bir konuma gelmesini sağlayabilecektir. O halde restoran yönetimleri müşterileri etkileyen ve restoranın tercih edilmesinde etkili olan faktörleri yakından tanımalidir (Siew vd., 2017).

\subsection{Analitik Hiyerarşi Süreci (AHS)}

Analitik Hiyerarşi Süreci (AHS), araştırmacılar tarafından kriterleri önceliklendirmek üzere yaygın olarak uygulanan çok kriterli bir karar verme (ÇKKV) yöntemidir. Saaty tarafından geliştirilen AHS yöntemi, çok kriterli bir karar verme probleminde alternatiflerin nispi önemini (ve dolayısıyla önceliğini) belirlemek için bir ikili karşılaştırma süreci kullanmaktadır. AHS, karmaşık ve yapılandırılmamış bir sorunu bir hiyerarşi halinde düzenlenmiş bir değişkenler kümesine ayrıştırmayı kapsamaktadır. Karar vericilerin önceliklerini formüle ederek çeşitli alternatifler ve kriterler arasından seçim yapabilmelerini 
sağlar. AHS, birçok farklı alanda (pazarlama, muhasebe, denetim, vb.) yaygın olarak kullanılabilmektedir (Chow ve Luk, 2005).

AHS, tek karar verici tarafından kullanılabildiği gibi aynı zamanda bir grup karar vericinin sağladığı hiyerarşi ve yargısal verilerin tutarlılığını önceliklendirebilen bir karar teorisidir. AHS, bütün karar vericilerin değerlendirmelerini, öznel ve nesnel ölçütler üzerinde fayda fonksiyonlarını ortaya çıkarmak zorunda kalmadan, nihai bir şekilde, Saaty ölçeğini (Tablo 1) kullanmak sureti ile karşılaştırmalı olarak ortaya koymaktadır (Wu vd., 2007).

Tablo 1. Saaty AHP İkili Karşılaştırma Ölçeği

\begin{tabular}{cl}
\hline Önem Değerleri & \multicolumn{1}{c}{ Değer Tanımları } \\
\hline 1 & Her iki faktörün eşit öneme sahip olması durumu \\
\hline 3 & 1. Faktörün 2. Faktörden daha önemli olması durumu \\
\hline 5 & 1. Faktörün 2. Faktörden kuvvetle daha önemli olması durumu \\
\hline 7 & 1. Faktörün 2. Faktöre nazaran yüksek derecede önemli olması \\
\hline 9 & 1. Faktörün 2. Faktöre nazaran çok yüksek derecede önemli olmas1 \\
\hline $2,4,6,8$ & $\begin{array}{l}\text { İki faktör arasındaki tercihte yukarıdaki açıklamalarda bulunan derecelerin ara } \\
\text { değerleridir. }\end{array}$ \\
\hline
\end{tabular}

Kaynak: (Göral, 2015)

Karar probleminin hiyerarşi olarak yapılandırılması (1), Her bir hiyerarşik düzeydeki kriterlerin ikili karşılaştırma ile karara bağlanması (2) ve Karar alternatiflerinin bileşik ağırlıklarının belirlenmesi (3), AHS'deki üç ana adımdır (Bayraktar, vd., 1999).

AHS uygulamasında ilk adımda, çoklu kriter karar verme problemi, dikkate alınan ana unsurları belirlemek suretiyle bir hiyerarşik yapıya dönüştürülür. Yapılandırma süreci, genel amacın hiyerarşinin en üstünde belirlenmesiyle başlar ve kriterler, alt kriterler ve karar alternatifleri alt seviyelere yerleştirilmek suretiyle karar probleminin hiyerarşik yapısı oluşturulmuş olur (Şekil 1).

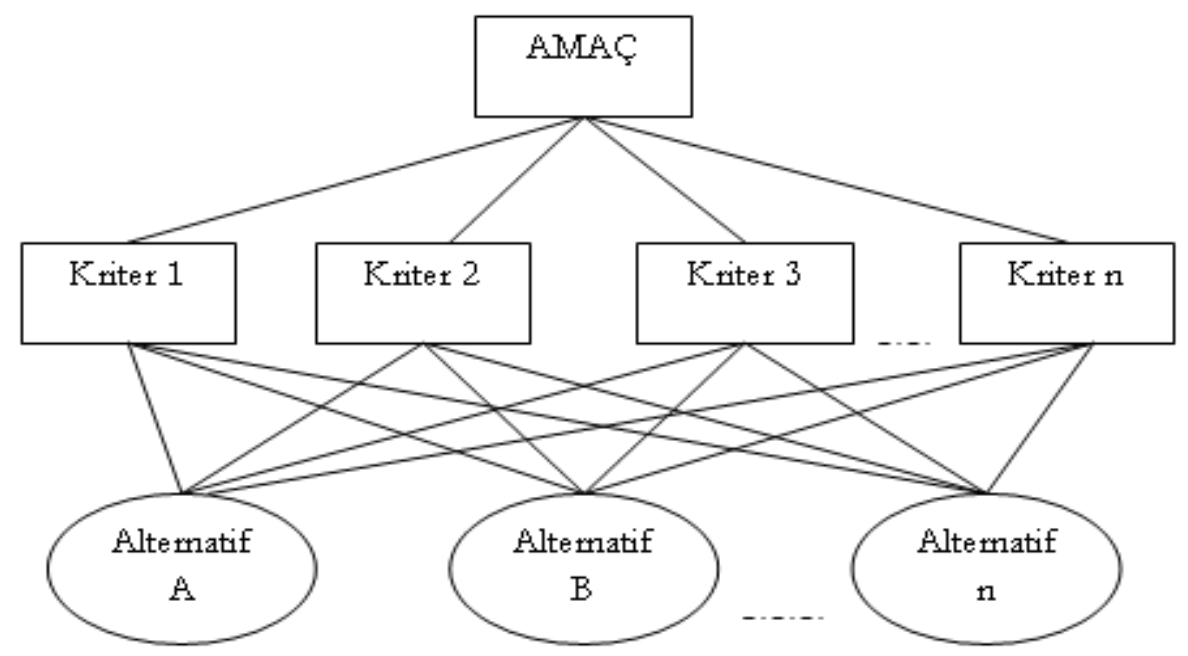

Şekil 1. AHS'nin Hiyerarşik Yapısı

Kaynak: (Göral, 2015) 
İkinci aşamada, karar vericilerden, ilk aşamada oluşturulan hiyerarşinin her bir elemanının her bir seviyedeki nispi önemini değerlendirmek için ikili karşılaştırmalar yapmaları istenir. Karşılaştırma süreci için Saaty tarafından geliştirilen ölçek kullanılır. İkili karşılaştırmalarla elde edilen nicel kararlar, karşıllaştırma matrisleri olarak adlandırılan kare matrislere transfer edilir. Karşılaştırma matrislerinin oluşturulmasından sonra, nispi ağırlıklar hesaplanır (Bayraktar vd., 1999).

Karş1laştırma matrisi, kriterlerin birbirlerine göre önem seviyelerini gösterir. Ancak bu kriterlerin bütün içerisindeki ağırlıklarını, diğer bir deyişle yüzde önem dağılımlarını belirlemek için, karşılaştırma matrisini oluşturan sütun vektörlerinden yararlanılır ve $\mathrm{n}$ adet ve n bileşenli B sütun vektörü oluşturulur (Göral, 2015). Aşağıda bu vektör gösterilmiştir:

$$
B_{i}=\left[\begin{array}{c}
b_{11} \\
b_{21} \\
\cdot \\
\cdot \\
\cdot \\
b_{n 1}
\end{array}\right]
$$

B sütun vektörlerinin hesaplanmasında $b_{i j}=\frac{a_{i j}}{\sum_{i=1}^{n} a_{i j}}$ formülünden yararlanılır.

Yukarıda anlatılan adımlar diğer değerlendirme kriterleri içinde tekrarlandığında kriter sayısı kadar B sütun vektörü elde edilecektir. $n$ adet B sütun vektörü, bir matris formatında bir araya getirildiğinde ise aşağıda gösterilen $\mathrm{C}$ matrisi oluşturulacaktır:

$$
C=\left[\begin{array}{cccc}
c_{11} & c_{12} & \ldots & c_{1 n} \\
c_{21} & c_{22} & \ldots & c_{2 n} \\
\cdot & & & \cdot \\
\cdot & & & \cdot \\
\cdot & & & \cdot \\
c_{n 1} & c_{n 2} & \ldots & c_{n n}
\end{array}\right]
$$

C matrisinden yararlanarak, kriterlerin birbirlerine göre önem değerlerini gösteren yüzde önem dağılımları elde edilebilir. Bunun için (1) formülünde gösterildiği gibi C matrisini oluşturan satır bileşenlerinin aritmetik ortalaması alınır ve Öncelik Vektörü olarak adlandırılan W sütun vektörü elde edilir. W vektörü aşağıda gösterilmiştir.

$$
w_{i}=\frac{\sum_{j=1}^{n} c_{i j}}{n}
$$




$$
W=\left[\begin{array}{c}
w_{1} \\
w_{2} \\
\cdot \\
\cdot \\
\cdot \\
w_{n}
\end{array}\right]
$$

Daha sonra bir önceki adımda elde edilen karşılaştırma matrislerinin tutarlılıkları araştırılır. AHS, elde edilen Tutarlılık Oranı (CR) ile bulunan öncelik vektörünün ve dolayısıyla kriterler arasında yapılan birebir karşılaştırmaların tutarlılığının test edilebilmesi imkanını sağlamaktadır. AHS, CR hesaplamasının özünü, kriter sayısı ile Temel Değer adı verilen $(\lambda)$ bir katsayının karşılaştırılmasına dayandırmaktadır. $\lambda$ 'nın hesaplanması için öncelikle A karşılaştırma matrisi ile W öncelik vektörünün matris çarpımından $\mathrm{D}$ sütun vektörü elde edilir.

$$
D=\left[\begin{array}{cccc}
a_{11} & a_{12} & \ldots & a_{1 n} \\
a_{21} & a_{22} & \ldots & a_{2 n} \\
\cdot & & & \cdot \\
\cdot & & & \cdot \\
\cdot & & & \cdot \\
a_{n 1} & a_{n 2} & \ldots & a_{n n}
\end{array}\right] x\left[\begin{array}{c}
w_{1} \\
w_{2} \\
\cdot \\
\cdot \\
\cdot \\
w_{n}
\end{array}\right]
$$

Bulunan D sütun vektörü ile W sütun vektörünün karş1lıklı elemanlarının bölümünden her bir değerlendirme kriterine ilişkin değer (E) elde edilir. Bu değerlerin aritmetik ortalaması (2) ise karşılaştırmaya ilişkin temel değeri $(\lambda)$ verir. $\lambda$ hesaplandıktan sonra Tutarlılık Göstergesi (CI), (3) formülünden yararlanarak hesaplanabilir. Son aşamada ise CI, Random Gösterge (RI) olarak adlandırılan ve Tablo 2' de gösterilen standart düzeltme değerine bölünerek (4) CR elde edilir.

$$
\lambda=\frac{\sum_{i=1}^{n} E_{i}}{n}
$$

$$
C I=\frac{\lambda-n}{n-1} \quad \text { (3) } \quad C R=\frac{C I}{R I}
$$

Hesaplanan CR değerinin 0.10 dan küçük olması karar vericinin yaptığı karşılaştırmaların tutarlı olduğunu gösterir. CR değerinin 0.10 ' dan büyük olması ya AHS' deki bir hesaplama hatasını ya da karar vericinin karşılaştırmalarındaki tutarsızlığını gösterir. 
Tablo 2. Rassal İndeks (RI) Değerleri

\begin{tabular}{cccccccccccccccc}
\hline $\mathbf{N}$ & $\mathbf{1}$ & $\mathbf{2}$ & $\mathbf{3}$ & $\mathbf{4}$ & $\mathbf{5}$ & $\mathbf{6}$ & $\mathbf{7}$ & $\mathbf{8}$ & $\mathbf{9}$ & $\mathbf{1 0}$ & $\mathbf{1 1}$ & $\mathbf{1 2}$ & $\mathbf{1 3}$ & $\mathbf{1 4}$ & $\mathbf{1 5}$ \\
\hline $\mathrm{RI}$ & 0 & 0 & 0,58 & 0,90 & 1,12 & 1,24 & 1,32 & 1,41 & 1,45 & 1,49 & 1,51 & 1,48 & 1,56 & 1,57 & 1,59 \\
\hline
\end{tabular}

Kaynak: (Göral, 2015)

Bütün bu süreçlerden sonra alternatif ve kriterlere ait önem dereceleri (ağırlıklar) belirlenir. En yüksek ağırlığa sahip olan alternatif en iyi alternatif, en yüksek ağırlığa sahip olan kriter en önemli kriter olarak belirlenir.

\subsection{Fast Food Sektöründe AHS Yöntemiyle Yapılmış Çalışmalar}

Fast food işletmeleri sektörünün dünya çapında hızla büyümesi araştırmacıların ilgisini bu sektöre çekmiştir. Fast food sektöründe AHS yöntemi kullanılarak yapılan pek çok araştırma bulunmaktadır. Bunlardan bazıları şunlardır;

Chow ve Luk (2005), yapmış oldukları çalışmada fast food restoran sektöründe hizmet kalitesi ölçümünde AHS yöntemini kullanmışlardır (Chow ve Luk, 2005).

Siew vd. (2017) yapmış oldukları çalışmada fast food restoran seçiminde etkili olan fiyat, müşteri hizmetleri, çevre, esneklik, etkinlik, lokasyon ve temizlik faktörlerinin önem sıralamasını yapmışlardır. Sıralamada AHS yöntemini kullanmışlardır (Siew, vd., 2017).

Kecek ve Gürdal (2016) yapmış oldukları çalışmada Dumlupınar Üniversitesi İİBF'de okuyan öğrencilerin fast food restoranlarını tercih ederken göz önünde bulundurdukları faktörleri (fiyat, lezzet ve tazelik, hizmet hızı, personelin tutumu, reklam) ve Burger King, McDonalds, Mr. Kumpir, Pizza Pizza, Popeyes, Sbarro fast food restoranlarını AHS yöntemi kullanılarak karşılaştırmışlardır. Araştırma bulgularına göre lezzet ve tazelik tüketicilerin en fazla önem verdiği tercih faktörüdür. Burger King ise en fazla tercih edilen fast food markasıdır (Kecek ve Gürdal, 2016).

Siew vd. (2018) Malezya'da fast food restoranlarını tüketici bakış açısıyla karşılaştırmışlardır. Çalışmada fiyat, müşteri hizmetleri, çevre, etkinlik, esneklik ve konum kriterleri kapsamında McDonald, KFC, Pizza Hut, Domino Pizza ve Wing Zone markaları değerlendirilmiştir. Markaların karşılaştırılması analizinde AHS-TOPSIS yöntemleri birlikte kullanılmıştır. Çalışma bulgularına göre McDonald, diğer fast food markalarına göre daha fazla tercih edilmektedir (Siew, vd., 2018).

\section{METOD}

Çalışmada tüketicilerin restoran seçimlerinde etkili olduğu düşünülen dokuz faktör ( yiyeceklerin tadl ve kalitesi, temizlik, personelin yardım severliği ve tutumu, menü çeşitliliği, servis hızl, restoranın konumu, fiyat, ortam/ambiyans, marka bilinirliği) AHS modeli kullanılmak suretiyle önceliklendirilmiştir. Böylece fast food restoranlarda müşterileri 
etkileyen ve restoranın tercih edilmesinde etkili olan faktörleri yakından tanımak mümkün olabilecektir.

Araştırmanın verileri anket yöntemiyle toplanmıştır. Saaty 1-9 ölçeğine göre hazırlanmış anket formu Selçuk Üniversitesi Beyşehir Ali Akkanat Kampusünde farklı programlarda okuyan (önlisans ve lisans) 180 öğrenciye Aralık 2018'de uygulanmıştır. Daha sonra her bir karar vericinin (öğrencinin) kriterlere ilişsin kişisel yargıları, geometrik ortalama yoluyla grup ortak kararına dönüştürülerek Super Decision programında kriter ağırlıkları hesaplanmıştır.

Çalışmanın analiz kısmında aşağıdaki sıralama takip edilmiştir:

1. Karar probleminin tanımlanması, amaç, kriterler açık bir şekilde belirlenerek hiyerarşik modelin oluşturulması,

Analizin karar problemi ve amacı, müşterilerin vermiş olduğu puanlar kapsamında fast food restoranların tercih edilmesinde rol oynayan faktörlerin öncelik sıralamasının yapılmasıdır. Fast food restoranların tercih edilmesinde rol oynayan faktörler (yiyeceklerin tadı ve kalitesi, temizlik, personelin yardım severliği ve tutumu, menü çeşitliliği, servis hızı, restoranın konumu, fiyat, ortam/ambiyans, marka bilinirliği) karar kriterleri olarak belirlenmiştir. Bu bilgiler 1şı̆̆ında karar probleminin hiyerarşik modeli Şekil 2'deki gibi oluşturulmuştur.

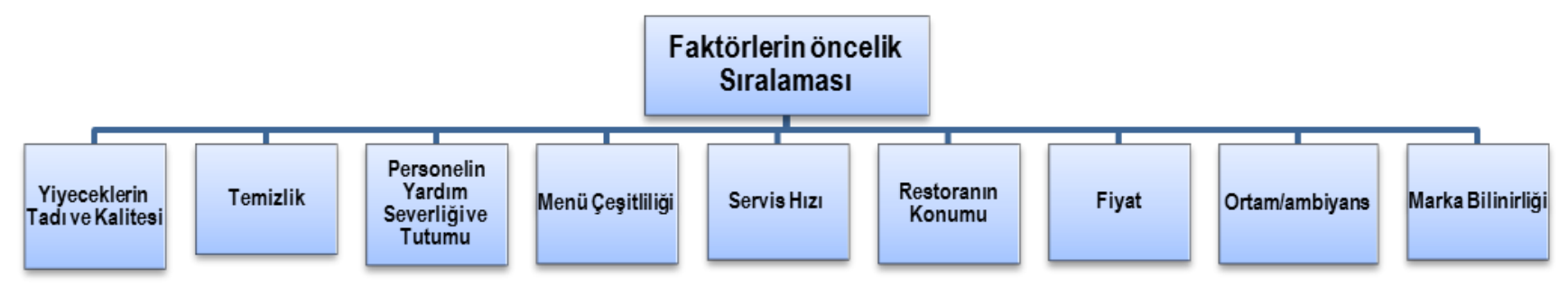

Şekil 2. Karar Probleminin Hiyerarşik Yapısı

2. Hiyerarşinin her seviyesi için kriterlerin ikili karşılaştırılması yapılarak kriterlerin önem derecelerinin (ağırlıklarının) belirlenmesi,

Modelde tüm kümeler, dügümler oluşturulduktan sonra kriterler kümesinde bulunan amaç düğümü dikkate alınarak karşılaştırılmıştır. Karşılaştırmada kullanılan veriler, Saaty'nin 1-9 ölçeği (Tablo-1) kullanılarak öğrencilerin kişisel yargılarının geometrik ortalaması alınmıştır. Hesaplanan geometrik ortalama değeri 1-9 arasında ise karşılaştırma sonucu Super Decision programı anket formunun sol tarafına değişiklik yapılmadan 
girilmiştir. Geometrik ortalama ondalıklı bir sayı ise yakın olduğu tamsayı değeri alınmıştır. Karar vericilere ait hesaplanan geometrik ortalama değeri 0-1 aralığında ise "1" değeri, bu değere bölünür ve çıkan sayı (1/sayı) şeklinde yazılır. Örneğin 1/0,20=1/5). Bölme sonucu elde edilen değer ondalıklı çıkması halinde yakın olduğu tam sayı değeri dikkate alınarak "1/ elde edilen değer” şeklinde Super Decision programı anket formunun sağ tarafına girilmiştir (Göral, 2015).

Karşılaştırmalardaki tutarsızlık, sıralama öncelik değerlerinin yanlış olması sonucunu doğurabilir. Tutarsızlık oranının "0" olması karar verici yargılarında tümü ile tutarlı olduğunu göstermektedir. Bu oranın \%10 ve daha aşağı olması genellikle kabul edilebilir bulunmaktadır (Göral, 2015). Çalışmada karar vericilerin bireysel yargılarının ikili karşılaştırmalarının tutarsızlık değeri $(0,013<0,10)$ kabul edilebilir sınırlar içinde olduğu görülmüştür.

\begin{tabular}{|c|c|c|}
\hline \multicolumn{3}{|c|}{ Inconsistency: 0.01378} \\
\hline Fiyat & & 0.03803 \\
\hline Marka Bil & & 0.05551 \\
\hline Menü Çeși & & 0.05551 \\
\hline Ortam/Amb & & 0.05551 \\
\hline Personeli & & 0.09727 \\
\hline Restoranı & & 0.04889 \\
\hline Servis $\mathrm{HI} \sim$ & & 0.08920 \\
\hline Temizlik & & 0.32573 \\
\hline Yiyecekle & & 0.23434 \\
\hline
\end{tabular}

Şekil 3. Super Decisin Programı Ekran Görüntüsü (Tutarsızlık-Inconsistency)

$\mathrm{Bu}$ bağlamda karar vericilerin (öğrencilerin) ikili karşılaştırmaları sonucu oluşan kriterlerin öncelik sıraları tablo 3'deki gibidir.

Tablo 3. Fast Food Restoranların Tercih Edilmesinde Rol Oynayan Faktörlerin Öncelik Sıralaması

\begin{tabular}{lc}
\hline \multicolumn{1}{c}{ KRITERLER } & ÖNCELIKKLENDİRME PUANI \\
\hline Temizlik & 0,325 \\
\hline Yiyeceklerin Tadı ve Kalitesi & 0,234 \\
\hline Personelin Yardım Severliği ve Tutumu & 0,097 \\
\hline Servis Hızı & 0,089 \\
\hline Marka Bilinirliği & 0,056 \\
\hline Menü Çeşitliliği & 0,056 \\
\hline Ortam/Ambiyans & 0,056 \\
\hline Restoranın Konumu & 0,049 \\
\hline Fiyat & 0,038 \\
\hline
\end{tabular}

Tablo 3'te görüleceği üzere fast food restoranlarının tüketiciler tarafından tercih edilmesinde en fazla etkili olan faktör Temizliktir. İkinci sırada ise Yiyeceklerin Tadı ve Lezzeti faktörü gelmektedir. Marka bilinirliği, Menü Çeşitliliği ve Ortam/Ambiyans eşit 
öncelik sırasına sahiptirler. Fiyat faktörü ise mevcut faktörler arasında tüketici tercihlerinde en az etkili faktör olarak değerlendirilmiştir.

\section{SONUÇ}

İnsan ve toplum davranışları üzerine yapılan inceleme sonuçları, toplumdan topluma, insandan insana ve zamana göre değişebilmektedir. Nitekim değişen zaman ve teknolojik gelişmelere göre insanların/ toplumların davranış kalıpları, tüketim durumları, tercihleri ve gereksinimleri değişim gösterebilmektedir (Bahar ve Kozak, 2013, s. 3). Bu bağlamda çalışma bulgularıyla örtüşen başka çalışmalar bulunmakla birlikte bulguların farklılık gösterdiği çalışmalar da mevcuttur.

Medeiros ve Salay (2013) tüketiciler tarafından yiyecek-içecek hizmeti sunan işletmeler tercih edilirken göz önünde bulundurulan faktörlere ilişkin literatür incelemesi yapmışlardır. $\mathrm{Bu}$ inceleme Scopus, Sciele ve Web of Science'da yer alan 45 çalışmayı kapsamaktadır. Bu literatür çalışmasına göre fast food restoranlarının seçiminde etkili olan en önemli faktörler sırasıyla; 1) Fiyat, 2) Servis Hızı ve Kalitesi, 3) Temizlik, 4) Yiyeceklerin Tadı ve Lezzeti, 5) Personelin Tutum ve Davranışları şeklindedir (Medeiros ve Salay, 2013).

"Fiyat" analiz edilen çalışmalarda en fazla araştırılan faktördür $(\% 64,4)$. Fiyat faktörünün, çalışmaların büyük çoğunluğunda yemek hizmeti sunan bir işletmenin seçiminde çok önemli bir faktör olduğu görülmüştür. Fiyatın, öğrenciler için en önemli faktör olduğu aynı zamanda düşük gelirli nüfus için de önemli bir faktör olduğu çalışmalarda vurgulanmaktadır. Bununla birlikte 6 çalışmada fiyat, diğer faktörlere kıyasla çok az önem verilen bir faktör olarak değerlendirilmiştir (Medeiros ve Salay, 2013).

Yaptığımız çalışmada hedef kitle öğrenciler olmasına karşın "fiyat" faktörü tüketici tercihlerinde en az dikkate alınan faktör olarak gözlemlenmiştir. Bu bağlamda çalışmamız sonucunda ortaya çıkan sıralamada fiyat faktörünün önem derecesi literatür incelemesi genel sonuçlarından ayrışan bir özellik göstermektedir.

Yiyecek içecek işletmelerinin tercih edilmesinde etkili olan faktörlere yönelik yapılan çalışmalarda en çok çalışılan faktörlerden bir diğeri ise "Servis"e ilişkin özelliklerdir. Servis Hızı, elde edilen bulgular doğrultusunda tüketiciler için orta derecede önemli bir faktördür. Tüketiciler, bir restoran seçiminde çalışanların davranışlarını en önemli faktör olarak görmektedirler. Yapılan bir çalışmada tüketiciler için en önemli faktörün çalışanların hijyenik olması sonucuna varılmıştır. Başka bir çalışmada ise çalışanların hizmet etmeye istekli ve hazır olmaları en önemli faktördür. Çalışanların güler yüzlü olması yiyecek içecek işletmelerinin tercih edilmesinde önemli olan bir diğer husustur (Medeiros ve Salay, 2013). 
Yaptığımız çalışmada “Personelin Yardım Severliği ve Tutumu” tüketiciler tarafından üçüncü sırada, "Servis Hızı” ise dördüncü sırada önemli bir faktör olarak değerlendirilmiştir. $\mathrm{Bu}$ bağlamda çalışmamızda yer alan sıralamada personelin yardım severliği ve tutumu ve servis hızı faktörünün yeri literatür incelemesi genel sonuçlarıyla örtüşen bir özellik göstermektedir.

Restoran hizmetlerinin seçiminde değerlendirilen bir diğer faktör de "Temizlik"tir. Çalışmalarda restoranın genel görünümü, mutfak, çatal, kaşık, porselen eşya, yemek alanı ve tuvaletlerin temizliği, tüketiciler tarafından restoranın hijyen seviyesini belirlemeye yönelik unsurlar olarak ortaya çıkmaktadır. $\mathrm{Bu}$ bağlamda tüketicinin hijyen güvenliği algısı, restoranın seçimini etkileyebilmektedir (Medeiros ve Salay, 2013).

Yaptığımız çalışmada “Temizlik” faktörü tüketiciler tarafından en önemli faktör olarak değerlendirilmiştir. Bu bağlamda çalışmamızda yer alan sıralamada temizlik faktörünün yeri literatür incelemesi genel sonuçlarıyla örtüşen bir özellik göstermektedir.

Yiyeceklerin kalitesi, restoranın seçiminde en önemli faktörlerden birisidir. Yiyeceklerin kalitesi, tüketici memnuniyetini de etkilemektedir. Sunulan yemek çeşidi, bir restoranın seçiminde en önemli unsurdur. Yine yapılan çalışmalar göstermiştir ki restoran seçimine en çok katkı sağlayan özelliklerden bir diğeri de yiyeceklerin tadıdır. Restoran menüsünün çeşitliliği gıda hizmetlerinin seçiminde bir başka ilgili faktörü oluşturmaktadır. Menü çeşitliliği, belirli bir yiyecek hizmetine ilişkin tüketici sadakatini ve memnuniyetini etkilemektedir. Restoran seçiminde etkili olan yiyecek ile ilgili diğer faktörler şunlardır; besin değeri, görünüm, porsiyon büyüklüğü, servis edilen yiyeceklerin sıcaklığı, tazelik, müşteri tarafından siparişi verilen yiyeceklerin sunumu ve restoranın sağlıklı beslenmeye uygun gıdalar sunmasıdır (Medeiros ve Salay, 2013).

Yaptığımız çalışmada "Yiyeceklerin Tadı ve Kalitesi” tüketiciler tarafından ikinci sırada önemli bir faktör olarak değerlendirilmiştir. "Menü Çeşitliliği” ise altıncı sırada önemli bir faktör olarak değerlendirilmiştir. Bu bağlamda çalışmamızda yer alan sıralamada yiyeceklerin tadı ve lezzeti ve menü çeşitliliği faktörünün yeri literatür incelemesi genel sonuçlarıyla örtüşen bir özellik göstermektedir.

Medeiros ve Salay (2013) tarafından yapılan analiz çalışmasına göre 45 makaleden \% 33,3’ünde ortam/ambiyans faktörü, restoran seçimini etkileyen faktörler arasında yer almıştır. Restoran ortam özellikleri açısından orta derecede önemlidir. Ortama ilişkin özellikler ise çekici bir dış tasarım, sigara içenler için bir alanın bulunması, sakin bir ortam, uygun bir müzik, geniş bir yemek alanı, gizlilik ve konfordur (Medeiros ve Salay, 2013). 
Çalışmamızda ortam ve ambiyans yedinci sırada önemli faktör olarak değerlendirilmiştir. Dolayısıyla literatür incelemesine uygun bir derecelendirmeye sahip olduğu söylenebilir.

Çalışmaların \% 44.4'ünde "konum” faktörü araştırmaya dahil edilmiştir. Yapılan çalışmalar konumun, yiyecek servisi veren işletmelerin seçiminde önemli bir faktör olmakla birlikte diğer faktörlerle kıyaslandığında sonlarda yer aldığını göstermiştir. Restoranın işyerine yakınlığı, okula yakınlığı gibi konum özelliği tercih edilme sebebidir (Medeiros ve Salay, 2013).

Çalışmamızda konum sekizinci sırada önemli faktör olarak değerlendirilmiştir. Dolayısıyla literatür incelemesine uygun bir derecelendirmeye sahip olduğu söylenebilir.

Araştırmalara göre restoranın diğer müşteriler tarafından tavsiye edilmesi önemli bir seçim unsurudur. Gregory ve Kim'in (2004), yapmış oldukları çalışmada restoran seçimini en fazla etkileyen bilginin arkadaş ve akrabalar tarafından verildiğini ( $\% 94.5)$, bu bilginin medyadan elde edilenden daha fazla kullanıldığını göstermiştir (Gregory ve Kim, 2004). Bunun yanında müşteri ilişkileri, çocuklara yönelik uygulamalar, içki servisi yapılıyor olması yemek hizmeti veren işletmelerin seçiminde etkili olan diğer hususlardır (Medeiros ve Salay, 2013).

Yapılan bu çalışma analize yer vermesi ve analiz sonuçlarının bir literatür taramasıyla karşılaştırılması açısından önemlidir. Bu özelliği ile çalışmamız ilgili alanda bundan sonra yapılacak başka çalışmalara da katkı sağlayabilecektir. Ayrıca restoran işletmecileri ve yöneticileri için de tüketicilerin restoran seçiminde göz önünde bulundurdukları faktörlerin önem derecesini görmelerine ve pazarlama faaliyetlerinde bunu dikkate alarak rekabet güçlerini artırmalarına yardımcı olabilecektir.

\section{KAYNAKÇA}

Azim, A., Shah, N. A., Mehmood, Z., Mehmood, S., \& Bagram, M. M. (2014). Factors Effecting the Customers Selection of Restaurants in Pakistan. International Review of Management and Business Research, Vol.3, Issue. 2, 1003-1013.

Aziz, F., \& Bukhari, A. (2009). Predilection of Adolescent Towards Fast Food. 5th ISOSS International Research Conference.

Bahar, O., \& Kozak, M. (2013). Turizm Ekonomisi. Ankara: Detay Yayınc1lı.

Bayraktar, D., Gözlü, S., \& Büyükdemir, B. (1999). An Application of Analytic Hierarchy Process in the Hospitality Industry. D.E.Ü. IIIBF Dergisi, Cilt:14,Sayı:1, 37-46.

Chow, C. C., \& Luk, P. (2005). A Strategic Service Quality Approach Using Analytic Hierarchy Process. Managing Service Quality, Vol.15, No.3, 278-289.

Ehsan, U. (2012). Factors Important for the Selection of Fast Food Restaurants: an Empirical Study Across Three Cities of Pakistan. British Food Journal, Vol.114, Issue:9, 1251-1264.

Goyal, A., \& Singh, N. (2007). Consumer Perception About Fast Food in India: An Exploratory Study. British Food Journal, Vol.109, No.2, 182-195.

Göral, R. (2015). E-WOM'a Dayalı Çok Kriterli Karar Verme Teknikleri ile En uygun Otelin Belirlenmesi ve Bir Uygulama. Selçuk Üniversitesi Sosyal Bilimler Enstitüsü Dergisi, Vol.33, 1-7. 
Gregory, S., \& Kim, J. (2004). Restaurant Choice: The Role of Information. Journal of Foodservice Business Research, Vol.7, No.1. 81-95.

Kecek, G., \& Gürdal, H. (2016). Determination of Preference Ranking of Fast Food Companies with Analytic Hierarchy Process: An Application in Dumlupinar University. European Journal of Business and Management, Vol.8, No.5, 28-34.

Mammadli, A. (2016). Consumer Perceptions of the Fast Food Industry in Sweden a Quantitative Research Study. Lund University.

Marketing Türkiye. (2017, 11 20). Türkiye'de Fast Food Sektörü. Türkiye.

Medeiros, C. O., \& Salay, E. t. (2013). A Review of Food Service Selection Factors Important to the Consumer. Food and Public Health, Vol.3(4),176-190.

Parsa, H., Gregory, A., \& Terry, M. (2011). Why Do Restaurants Fail? Part III: An Analysis of Macro and Micro Factors. Orlanda,USA: University of Central Florida Rosen College of Hospitality Management.

Saaty, T. L. (1980). The Analytic Hierarchy Process. New York: McGraw-Hill.

Siew, L. W., Hoe, L. W., Fai, L. K., \& Wai, C. J. (2018). An Empirical Study on the Preference of Fast Food Restaurants in Malaysia with AHP-TOPSIS Model. Journal of Engineering and Applied Sciences, 3226-3231.

Siew, L. W., Wai, C. J., \& Hoe, L. W. (2017). Analysis on the Preference of Fast Food Restaurants with analytic Hierarchy Process Model. International Journal of Psychology and Cognitive Science, Vol 3(6), 72-76.

Stewart, H., Blisard, N., Jolliffe, D., \& Bhuyan, S. (2005). The Demand for Food away from Home: Do Other Preferences Compete with Our Desire to Eat Healthfully"? Journal of Professional Services Marketing, Vol.30, no.3,520-536.

Wu, C. R., Lin, C. T., \& Chen, H. C. (2007). Optimal Selection of Location for Taiwanese Hospitals to Ensure a Competitive Advantage by Using the Analytic Hierarchy Process and Sensitivity Analysis. Building and Environment, 1431-1444.

\section{EXTENDED ABSTRACT}

Fast food is an increasingly popular food culture that has emerged as a result of the fact that people spend less time on eating to make more efficient use of time in the busy working and living conditions of urban areas. Fast food is preferred by a growing number of people due to its attractive advantages such as being prepared and served quickly and easily, providing onsite consumption and suitability for transportation as a package.

The rate of urbanization increases due to the rapid population growth throughout the world, and as a result of the increase in the number of women participating in working life, the income levels of the families are constantly rising. In addition, the intense pace of working life makes the time even more valuable and shortens the time allocated to eating and strengthens the habit of eating out. Fast food sector is growing day by day as the attractiveness of advertisements is added to the interest of young population in parallel with the increasing population. In connection with this growth, the competition conditions between companies that want to get a bigger share of the growing pie by meeting the demands and expectations of customers with different age, gender and social status are becoming more difficult. Therefore, restaurant managers need to be aware of customer perceptions and systematically check the consumer behaviour in order to determine factors that guide purchasing behaviour of consumers and to present value through these factors.

In this context, the study aims to prioritize the decision factors affecting the consumers' preference of fast food restaurants. As a result of examining the studies conducted in this area 
and the literature review, the nine main factors thought to be effective in the consumers' preference of a fast food restaurant have been identified. These factors are taste and quality of food, cleanliness, helpfulness and attitude of the staff, menu variety, service speed, restaurant location, price, environment / ambiance, brand recognition factors. These nine main factors thought to be effective in the consumers' preference of a fast food restaurant have been ranked by using the Analytical Hierarchy Process (AHS) method, one of the multi-criteria decision-making methods. Thus, the factors that are effective in the preference of fast food restaurants are prioritized according to consumer perspective.

The Analytical Hierarchy Process (AHS) is a multi-criteria decision-making (MCDM) method that is widely applied by researchers to prioritize criteria. The AHS method developed by Saaty uses a binary comparison process to determine the relative importance (and therefore the priority) of alternatives in a multi-criteria decision making problem. AHS includes separating a complex and unstructured problem into a set of variables arranged in a hierarchy. It enables decision-makers to choose among various alternatives and criteria by formulating their priorities. AHS can be widely used in many different areas (marketing, accounting, auditing, etc.)

In the study, nine factors (taste and quality of food, cleanliness, helpfulness and attitude of staff, menu variety, service speed, restaurant location, price, environment / ambiance, brand awareness) thought to be effective in restaurant preference of consumers were prioritized by using AHS model. Thus, it was aimed to show the enterprises the importance of factors affecting customers' preference of fast food restaurants and to guide them to use these factors more effectively in marketing activities.

The data of the study was collected by survey method. The questionnaire prepared by Saaty according to the 1-9 scale was applied to 180 students (associate and undergraduate) studying in different programs at Beyşehir Ali Akkanat Campus of Selçuk University in December 2018. Then, the personal judgment of each decision-maker (student) regarding the criteria was converted into a group decision by means of a geometric mean and the criteria weights were calculated in the Super Decision program. In the analysis part of the study, first the decision problem was defined, the hierarchical model was formed by determining the goals and criteria clearly and then, the significance levels (weight) of the criteria were determined by performing the binary comparisons of the criteria for each level of the hierarchy. In this context, the priority order of the factors resulting from the binary comparisons of decision makers (students) is listed as follows. 
Table 1. Priority Order of the Factors Affecting the Preference of Fast Food Restaurants

\begin{tabular}{lc}
\hline \multicolumn{1}{c}{ FACTORS } & PRIORITIZATION SCORE \\
\hline Cleanliness & 0,325 \\
\hline The taste and quality of food & 0,234 \\
\hline Helpfulness and Attitude of Staff & 0,097 \\
\hline Service Speed & 0,089 \\
\hline Brand awareness & 0,056 \\
\hline Menu Variety & 0,056 \\
\hline Environment / ambiance & 0,056 \\
\hline Restaurant Location & 0,049 \\
\hline Price & 0,038 \\
\hline
\end{tabular}

As seen in the table, the most effective factor in the preference of fast food restaurants by consumers is cleanliness. The second factor is taste and quality of food, the third is helpfulness and attitude of staff and the fourth is service speed. Brand awareness, menu variety and environment / ambiance have equal order of priority. Restaurant location is the eighth factor and price is the least effective factor in consumer preferences among the current factors.

As a result of our study, it is seen that the priority order generally corresponds with the results of the previous studies conducted in this field and literature findings. The most remarkable finding of the study is that the price factor has the lowest significance level among the nine factors effective in restaurant preferences.

Although the price factor is known to be the most important factor in many areas for the students, the target audience of the study, the fact that it has the lowest significance level as a result of the study shows a feature that differs from the general results of the literature review. This study is important since it includes analysis and compares the results of analysis with a literature review. With this feature, our study will be able to contribute to further studies in the related field. It can also help restaurant managers to see the significance levels of the factors affecting the restaurant preference of consumers and increase their competitive power by taking this into account in marketing activities. 